\title{
The incremental treatment of ESRD: a low-protein diet combined with weekly hemodialysis may be beneficial for selected patients
}

\author{
Stefania Caria ${ }^{1 *}$, Adamasco Cupisti ${ }^{2}$, Giovanna Sau $^{3}$ and Piergiorgio Bolasco ${ }^{1}$
}

\begin{abstract}
Background: Infrequent dialysis, namely once-a-week session combined with very low-protein, low-phosphorus diet supplemented with ketoacids was reported as a useful treatment schedule for ESRD patients with markedly reduced residual renal function but preserved urine output. This study reports our findings from the application of a weekly dialysis schedule plus less severe protein restriction (standard low-protein low-phosphorus diet) in stage 5 CKD patients with consistent dietary discipline.
\end{abstract}

Methods: This is a multicenter, prospective controlled study, including 68 incident CKD patients followed in a pre-dialysis clinic with Glomerular Filtration Rate 5 to $10 \mathrm{ml} / \mathrm{min} / 1.73 / \mathrm{m}^{2}$ who became unstable on the only medical treatment. They were offered to begin a Combined Diet Dialysis Program (CDDP) or a standard thrice-a-week hemodialysis (THD): 38 patients joined the CDDP, whereas 30 patients chose THD. Patients were studied at baseline, 6 and 12 months; hospitalization and survival rate were followed-up for 24 months.

Results: Volume output and residual renal function were maintained in the CDDP Group while those features dropped quickly in THD Group. Throughout the study, CDDP patients had a lower erythropoietin resistance index, lower $\beta 2$ microglobulin levels and lower need for cinacalcet of phosphate binders than THD, and stable parameters of nutritional status. At 24 month follow-up, 39.4\% of patients were still on CDDP; survival rates were 94.7\% and 86.8\% for CDDP and THD patients, respectively, but hospitalization rate was much higher in THD than in CDDP patients. The cost per patient per year resulted significantly lower in CDDP than in THD Group.

Conclusions: This study shows that a CDDP served to protect the residual renal function, to maintain urine volume output and to preserve a good nutritional status. CDDP also blunted the rapid $\beta 2$ microglobulin increase and resulted in better control of anemia and calcium-phosphate abnormalities. CDDP was also associated with a lower hospitalization rate and reduced need of erythropoietin, as well as of drugs used for treatment of calcium-phosphate abnormalities, thus leading to a significant cost-saving. We concluded that in selected ESRD patients with preserved urine output attitude to protein restriction, CDDP may be a beneficial choice for an incremental hemodialysis program.

Keywords: Nutrition, Low protein diet, Hemodialysis, CKD, ESRD, Incremental dialysis

\section{Background}

The Epidemiology of chronic kidney disease (CKD) is on an upward trend worldwide. Since the 1990s incidence has risen by approximately $40 \%$ per decade, with prevalence rates in the general adult population up to $13 \%$ in the USA and ranging 10.2-11.6\% in Europe [1-4]. These figures indicate a CKD epidemic leading to an increased

\footnotetext{
* Correspondence: cariastefan@tiscali.it

${ }^{1}$ Nephrology and Dialysis Unit, ASL 8 Cagliari, Italy

Full list of author information is available at the end of the article
}

number of patients requiring dialysis and a heavy burden on public health resources.

Nutritional and pharmacological therapy constitute the basis for the prevention and treatment of signs and symptoms of CKD, and they serve to delay the commencement of dialysis. The appropriate time to start dialysis is still a matter of debate. In particular, dialysis is not superior that conservative treatment especially in the comorbid-elderly population. It is known that a standard thrice-weekly hemodialysis schedule invariably leads to rapid loss of the 
residual renal function, to psychological and socials drawbacks, and to high costs. Real incremental dialysis programs are implemented in peritoneal dialysis but not in the hemodialysis setting where only a twice -weekly schedule may be proposed prior to maintenance hemodialysis.

During the 1980's and 1990's, an Integrated Diet Dialysis Program (IDDP) was proposed as a therapeutic option for selected patients with markedly reduced residual renal function and it consisted of weekly hemodialysis session (HD) combined with nutritional therapy, namely a very low-protein diet supplemented with ketoacids [5-8]. Malnutrition risk and low compliance to the severe dietary restrictions represented major concerns that prevented a widespread application of this schedule. In the present study we propose a Combined Diet Dialysis Program (CDDP) which includes a less severe low protein $(0.6$ $\mathrm{g} / \mathrm{Kg} / \mathrm{d}$ ) diet combined with once-weekly hemodialysis. The goal is to prolong a conservative approach and thus reduce the need for hemodialysis, thereby limiting the risk of malnutrition and of poor dietary adherence. This study aimed to assess the safety, benefits and drawbacks of the CDDP approach including nutritional status, residual renal function, morbidity, mortality and costs.

\section{Methods}

This is a multicenter, non-randomized, prospective controlled study, including stage V CKD patients followed in a pre-dialysis clinic who were not suitable for a peritoneal dialysis program.

Patients with GFR 5 to $10 \mathrm{ml} / \mathrm{min}$ who were approaching hemodialysis treatment and who had vascular access were included in the study. Global criteria of starting dialysis and then for entering the study were fluid retention, inadequate control of BUN or severe secondary hyperparathyroidism or hyperphosphatemia, reduced compliance to dietary treatment.

Patients with pericarditis, congestive heart failure, severe fluid retention, overt protein-energy wasting, hyperkalemia or severe metabolic acidosis with acute reduction of residual renal function or concurrent diseases were excluded, as well patients with unreliable discipline with regards to dietary restrictions were treated at once with maintenance hemodialysis and then excluded from the study. During the pre-dialysis phase, patients were followed in a tertiary care CKD clinic every two-three months (stage 4 ) or on a monthly basis (stage 5). Compliance to dietary and pharmacological treatment was acceptable, as assessed by urinary urea excretion and by dietary recall and interview.

Sixty-eight incident patients were recruited and all the patients were provided a functioning native arterovenous fistula or graft.
Underlying kidney diseases included mainly hypertension/vascular nephropathy, ADPKD. The patients were offered the choice to commence a weekly hemodialysis schedule plus low-protein diet on the non-dialysis day (namely, CDDP), or to begin a standard thrice- weekly hemodialysis (THD) schedule and free-choice diet. All the patients were informed and directly involved in the decision making process. Randomization was not applied since any dietary regimen requires adherence and motivation.

According to their own choice, 38 patients entered in the CDDP Group, whereas the remaining 30 patients formed the THD control group. The clinical and biochemical features of the two groups at baseline are reported in Table 1. At baseline, the prevalence of cardiovascular disease history was similar in CDDP (28.9\%) and in THD (30\%) group. Six type 2 diabetics were included in CDDP group and 13 in THD group.

All the patients were studied at baseline, and after 6 and 12 months. The survival rate and hospitalization rate were followed up to 24 months.

Blood samples were collected from the arterial line before the start of the first dialysis of the week; $24 \mathrm{~h}$ urines were collected during the day before the HD session. GFR was measured as the average of creatinine clearance and urea clearance, and expressed as $\mathrm{ml} / \mathrm{min}^{*} 1.73 \mathrm{~m}^{2}$ body surface area [9]; eGFR was also estimated by MDRD formula [10]. Protein catabolic rate (PCR) was used as an indicator of dietary protein intake and calculated by the urea appearance method according to Maroni's formula [11]. Maroni's formula was used throughout the course of the CDDP and only at baseline time in patients in the THD Group. Within the THD Group, for patients with the significant loss of renal function and urine output volume we included the method of urea kinetics model for estimation of nPCR. Dialytic adequacy was expressed

Table 1 Baseline characteristics of the studied groups

\begin{tabular}{|c|c|c|c|}
\hline & $\begin{array}{l}\text { CDDP group } \\
(n=38)\end{array}$ & $\begin{array}{l}\text { THD group } \\
(n=30)\end{array}$ & $\mathbf{p}$ \\
\hline Male/females & $25 / 13$ & $19 / 11$ & \\
\hline Age, years & $64.5 \pm 13.2$ & $65.2 \pm 11$ & 0.82 \\
\hline Body weight (kg) & $65.5 \pm 15.1$ & $66.2 \pm 11.9$ & 0.73 \\
\hline BMI $\left(\mathrm{kg} / \mathrm{m}^{2}\right)$ & $23.7 \pm 4.0$ & $25.6 \pm 4.13$ & 0.03 \\
\hline Urine volume output (mL/24 h) & $1983 \pm 651$ & $1472.6 \pm 433$ & $<0.001$ \\
\hline $\mathrm{GFR}(\mathrm{mL} / \mathrm{min} \times 1.73 \mathrm{mq}$ b.s $)$ & $7.8 \pm 1.9$ & $9.2 \pm 4.2$ & $<0.01$ \\
\hline EPO (IU/kg/week) & $104 \pm 108$ & $184 \pm 84$ & $<0.001$ \\
\hline CRP $<5 \mathrm{mg} / \mathrm{dl}, \%$ & 89 & 66.6 & $<0.01$ \\
\hline iPTH, >300 pg/mL, \% & 31.5 & 50 & $<0.01$ \\
\hline $\begin{array}{l}\text { Charlson comorbidity } \\
\text { index score }\end{array}$ & $5.5 \pm 2.5$ & $3.8 \pm 2.5$ & 0.004 \\
\hline $\begin{array}{l}\text { Charlson comorbidity } \\
\text { index score }>4, \%\end{array}$ & 62.5 & 33.3 & $<0.01$ \\
\hline
\end{tabular}


using eKt/V according to Daugirdas formula et al [12]. Body mass index was calculated by the body weight at the end of the dialysis session. The bioelectrical parameters, were measured with a single-frequency impedance analyzer (BIA 101 - Akern - Florence), 30' after the end of the hemodialysis session.

Erythropoietin Resistance Index (ERI) was calculated as weekly EPO dosage (units)/body weight (Kg)/ $\mathrm{Hb}(\mathrm{g} / \mathrm{dl})$ [13].

Charlson's comorbidity index (CCI) score, was calculated to evaluate comorbidity conditions [14].

Creatinine production, as a surrogate of muscle mass, was calculated by the sum of $24 \mathrm{~h}$ urine creatinine excretion and metabolized creatinine. Metabolized creatinine was calculated from the product of serum creatinine and extrarenal Creatinine clearance (estimated as 0.038 $\mathrm{L} / \mathrm{kg} \mathrm{BW/d)} \mathrm{[7].}$

All the patients on CDDP underwent nutritional counseling by a renal dietician and were prescribed a low protein $(0,6 \mathrm{~g} / \mathrm{kg}$ b.w./d), low phosphorus $(600-700 \mathrm{mg} / \mathrm{d})$, low sodium diet with an energy intake of $30-35 \mathrm{kcal} / \mathrm{kg} \mathrm{b}$. w./d. Proteins were mostly from animal sources $(0.4 \mathrm{~g} / \mathrm{Kg} /$ b.w.), to cover the requirement of essential amino acids; no dairy or processed foods are included to the aim of limiting the sodium and phosphorus intake; [15] protein-free products are included to supply energy with negligible load of phosphorus, sodium, potassium and nitrogen [16]. The $60-62 \%$ of energy intake derived from carbohydrates (mostly represented by protein-free products), 30-32\% from lipids and $8-10 \%$ from proteins. As average, the daily dietary plan consisted of 5-7 servings of protein free products, namely $2-3$ serving for breakfast and snacks and 2 servings for both lunch and dinner; the patients were usually advised that they can add other servings, when required to satisfy the energy requirement. The servings of animal protein sources (meat, fish, egg white) were calculated for each patient in order to guarantee a daily total amount of $0.4 \mathrm{~g}$ protein per $\mathrm{kg}$ b.w. Two servings of vegetables and two of fruits were provided with specific suggestions for patients with high potassium levels as well as boiling was suggested to reduce to mineral content (potassium, sodium, calcium, and phosphorus) of food. Finally, 5-6 servings of fats (olive oil as first choice) were suggested.

This diet was prescribed for 6 days a week, while no dietary restrictions occurred on the dialysis day.

Patients in the THD control group followed an unrestricted protein diet, but they were given dietary counseling focused on preventing excess sodium, potassium, phosphorus and fluid intakes.

All the patients were prescribed 4-hour hemodialysis sessions with highly biocompatible synthetic membranes.

The study protocol was approved by the Cagliari Hospital Ethics Committee, and all the patients gave their written informed consent for participation in the study.

\section{Statistical analysis}

Descriptive statistics is given as mean \pm standard deviation. Normality tests were performed on all continuous variables measured throughout the study. The log-rank test was used for hypothesis testing. Time repeated measurements were analyzed using linear mixed models including treatment, time, and treatment by time interaction for all measured variables using ANOVA. Inter-group drug use was compared by means of the binomial test with Bonferroni's correction for multiple comparisons.

Differences were considered as statistically significant when $\mathrm{p}<0.05$.

\section{Results}

Patients who entered the CDDP showed several differences with respect to patients who commenced THD (Table 1). Despite a lower residual renal function (RRF), CDDP patients showed lower circulating levels of phosphate, BUN, PTH and higher albumin levels with respect to THD patients. 34 out of the 38 patients were still on CDDP at 12 months: 2 patients were shifted to a thriceweekly dialysis schedule at 8 and 10 months, while 2 patients partially recovered their renal function and remained clinically stable with the low-protein diet and no need for dialysis.

During the study period, GFR was preserved in CDDP patients in comparison to THD group (Table 2). GFR loss progression was very low in the former $(-0.13 \mathrm{ml} / \mathrm{min} /$ month) while it was faster in the latter $(-1.53 \mathrm{ml} / \mathrm{min} /$ month). Similarly, in the CDDP group an effective urine volume output was maintained whereas it dramatically dropped in the THD patients (Figure 1a). As a consequence, the interdialytic weight gain in CDDP patients was limited to $(800 \pm 300 \mathrm{~g})$ per week. The dosage of frusemide increased from $150 \pm 154$ to $273 \pm 201 \mathrm{mg}$ /day in the CDDP group, and from $332 \pm 171$ to $409 \pm 205 \mathrm{mg} /$ day $(p=0.003)$ in the THD group. The increase of $\beta 2$ microglobulin circulating levels was much lower in CDDP than in THD patients $(+11.2 \%$ vs $+34 \%$, respectively) (Figure 1c).

No difference in arterial blood pressure values emerged between the two groups.

The main nutritional indicators, i.e. total protein, albumin and transferrin improved significantly in the CDDP group (Figure 1b, Table 2). Estimated dietary protein intake remained stable in the CDDP groups throughout the study (from $0.58 \pm 0.2$ to $0.57 \pm 0.11 \mathrm{~g} / \mathrm{kg} /$ day). This was also the case for THD patients (from $1.03 \pm 0.1$ to $1.04 \pm$ $0.3 \mathrm{~g} / \mathrm{kg} /$ day). No significative changes in body weight or Body Mass Index (BMI) were recorded in the two groups (Table 2).

A significant reduction in the ESAs requirement was observed in the CDDP group along with markedly lower ERI values (Table 3 ). 
Table 2 Outcome of nutritional and functional parameters in both groups in 12 months

\begin{tabular}{|c|c|c|c|c|c|c|c|}
\hline & CDDP grou & & & THD group & & & \\
\hline & $\begin{array}{l}\text { Baseline } \\
(n=38)\end{array}$ & $\begin{array}{l}6 \text { months } \\
(\mathrm{n}=38)\end{array}$ & $\begin{array}{l}12 \text { months } \\
(\mathrm{n}=34)\end{array}$ & $\begin{array}{l}\text { Baseline } \\
(n=30)\end{array}$ & $\begin{array}{l}6 \text { months } \\
(\mathrm{n}=30)\end{array}$ & $\begin{array}{l}12 \text { months } \\
(\mathrm{n}=29)\end{array}$ & $P$ \\
\hline Dry weight (kg) & $65 \pm 15.0$ & $63.9 \pm 14.4$ & $63.4 \pm 14.7$ & $66.2 \pm 11.9$ & $64.9 \pm 11.5$ & $65.5 \pm 12.3$ & 0.07 \\
\hline$B M I\left(\mathrm{~kg} / \mathrm{m}^{2}\right)$ & $23.7 \pm 4.0$ & $23.4 \pm 3.7$ & $23.0 \pm 3.9$ & $25.6 \pm 4.13$ & $25.1 \pm 4.07$ & $25.4 \pm 4.2$ & 0.07 \\
\hline Total body water (L) & $44.4 \pm 10.5$ & $41 \pm 9.6$ & $43 \pm 11$ & $35.4 \pm 6$ & $33.5 \pm 5.8^{a}$ & $33.8 \pm 5.9^{a}$ & 0.02 \\
\hline Extracellular water (L) & $20 \pm 4.5$ & $18.6 \pm 4.3$ & $19.7 \pm 4$ & $17.5 \pm 3.2$ & $16 \pm 2.8^{b}$ & $15.7 \pm 2.4^{b}$ & 0.04 \\
\hline Fat mass $(\mathrm{kg})$ & $11 \pm 12.3$ & $13 \pm 11.8$ & $11.4 \pm 11$ & $20 \pm 9$ & $21.4 \pm 8.5$ & $22.6 \pm 9.4$ & 0.03 \\
\hline Body cell mass $(\mathrm{kg})$ & $31 \pm 9.6$ & $28 \pm 8.9$ & $29.7 \pm 10.3$ & $22.5 \pm 6.2$ & $22.7 \pm 5$ & $22.7 \pm 5.8$ & 0.02 \\
\hline Phase angle, $\left({ }^{\circ}\right)$ & $6.2 \pm 1.3$ & $6.2 \pm 1.3$ & $6.1 \pm 1.4$ & $5.0 \pm 1.2$ & $6 \pm 0.9$ & $5.8 \pm 1.2$ & 0.06 \\
\hline$S B P(m m H g)$ & $139 \pm 18$ & $132 \pm 20$ & $128 \pm 15^{b}$ & $136.8 \pm 17.2$ & $138.5 \pm 18.5$ & $139 \pm 20.8$ & 0.21 \\
\hline$D B P(m m H g)$ & $80 \pm 12$ & $73 \pm 10$ & $74 \pm 9^{c}$ & $71.6 \pm 11.4$ & $71.6 \pm 10$ & $72.9 \pm 12.3$ & 0.08 \\
\hline Serum creatinine (mg/dL) & $6.4 \pm 1.9$ & $7.0 \pm 2.5$ & $7.8 \pm 3.0^{b}$ & $5.9 \pm 1.8$ & $7.8 \pm 2.2$ & $8.2 \pm 2.4^{b}$ & 0.05 \\
\hline B.U.N. $(\mathrm{mg} / \mathrm{dL})$ & $68 \pm 18$ & $68 \pm 16$ & $70 \pm 17$ & $84.4 \pm 18.5$ & $77 \pm 15.5$ & $77 \pm 22.9$ & 0.003 \\
\hline GFR (mL/min) & $7.8 \pm 1.9$ & $6.7 \pm 2.3$ & $6.3 \pm 2.1^{b}$ & $9.2 \pm 4.2$ & - & - & - \\
\hline eGFR (mL/min) & $9.4 \pm 2.9$ & $8.4 \pm 3.5^{a}$ & $8.0 \pm 3.4^{b}$ & $10.3 \pm 3.9$ & - & - & - \\
\hline Total protein $(\mathrm{g} / \mathrm{dL})$ & $6.7 \pm 0.5$ & $6.7 \pm 0.5$ & $6.8 \pm 0.4$ & $6.35 \pm 0.52$ & $6.4 \pm 0.5$ & $6.5 \pm 0.43$ & 0.004 \\
\hline Albumin $(\mathrm{g} / \mathrm{dL})$ & $3.8 \pm 0.4$ & $3.9 \pm 0.4$ & $4.1 \pm 0.4^{b}$ & $3.6 \pm 0.40$ & $3.6 \pm 0.37$ & $3.7 \pm 0.48$ & 0.01 \\
\hline Transferrine (mg/dL) & $219 \pm 53$ & $203 \pm 72$ & $222 \pm 53$ & $264 \pm 94$ & $249 \pm 43$ & $251 \pm 61$ & 0.001 \\
\hline C3 (mg/dL) & $90 \pm 20$ & $91 \pm 23$ & $94 \pm 23$ & $99.6 \pm 39.6$ & $96 \pm 35.7$ & $95.9 \pm 32$ & 0.48 \\
\hline C4 (mg/dL) & $24 \pm 7$ & $24 \pm 8$ & $26 \pm 7$ & $33 \pm 28$ & $29 \pm 18$ & $29 \pm 30$ & 0.26 \\
\hline Total lgG (mg/dL) & $1599 \pm 497$ & $1590 \pm 402$ & $1543 \pm 373$ & $1440 \pm 461$ & $1482 \pm 487$ & $1409 \pm 413$ & 0.21 \\
\hline Lynphocytes $/ \mathrm{mm}^{3}$ & $1539 \pm 651$ & $1390 \pm 831$ & $1581 \pm 537$ & $1452 \pm 811$ & $1458 \pm 622$ & $1445 \pm 580$ & 0.38 \\
\hline
\end{tabular}

Legend: changes versus baseline: ${ }^{a} p<0.05 ;{ }^{b} p<0.01 ;{ }^{c}<0.03$; P: ANOVA significance for treatment by time interaction.

Calcium phosphate metabolism parameters were stable and better controlled in the CDDP (Table 3, Figure 1d) group despite a significantly lower use of non-calcium containing phosphate-binders and cinacalcet and among all the drugs, only allopurinol use was reduced during THD (Table 4).

Calcimimetics drugs are not delivered by Italian NHS during the pre-dialysis phase.

So their use began after commencing dialysis (even once-a-week): patients on THD showed a secondary hyperparathyroidism more severe than patients on CDDP, consequently the need of calcimimetics was higher in the former than in the latter.

No significant reduction in creatinine production was observed after 12 months of CDDP (16.8 \pm 4.3 vs. $15.9 \pm$ $3.9 \mathrm{mg} / \mathrm{Kg} / \mathrm{d})$.

\section{Hospitalization}

Throughout the 24 month follow-up period, 3 CDDP patients were admitted to hospital for a total of 11 days $(3.7 \pm 1.5$ days/patient) due to atrial fibrillation, acute bronchitis and acute cholecystitis. Instead 24 hospital admission were recorded in 15 patients of THD groups for a total of 147 days (6.1 \pm 6.3 days/patient). Causes for admission were: set up of new vascular access (7), artero- venous fistula stenosis angioplasty (1), infection of central vein catheter (2), acute pulmonary edema (1), surgery for biological prosthetic valve (1), myocardial infarction (1), valvular and coronaropathy angioplasty (2), congestive heart failure (1), atrial fibrillation (2), hyperpyrexia (1), hypertensive crisis (1), hypoglycemic coma (1), abscess in thigh hematoma (1) and obstructive jaundice secondary to gallstones (2).

\section{Survival}

At the 24-month follow-up, no significant difference was detected between the CDDP and THD group survival rates: $94.7 \%$ and $86.8 \%$ respectively (Figure 2 ).

Death in 3 CDDP patients was caused by cardiac events: 1 during the 13th, 1 during the 16th and 1 during the 18th month of CDDP. Four deaths occurred in the THD group: 1 in the 9th, 2 in the 13th and 1 in the 22nd month following start of dialysis. Causes included myocardial infarction and acute heart failure, sepsis and stroke.

\section{CDDP global outcome}

At 12 months 34 out of the 38 patients (89.5\%) were on CDDP. At 24 months, 15 patients were still on CDDP (39.4\%) since 1 patient received a kidney transplant, 3 patients had fatal myocardial infarction, whereas 17 patients 
a

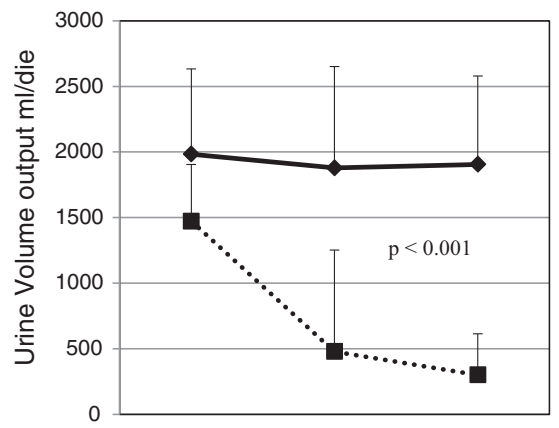

c

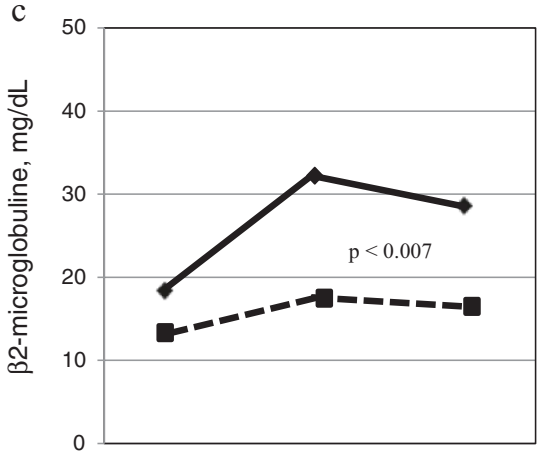

$\mathrm{b}$

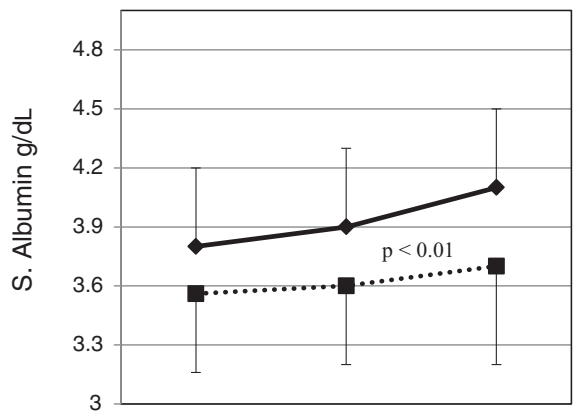

d

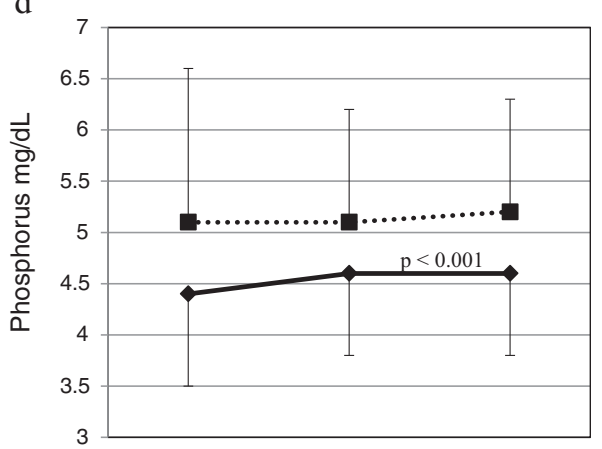

Figure 1 Changes in urine volume (a), serum albumin (b), $\beta 2$-microglobulin (c) and serum phosphorus (d) in CDDP Group (dotted Line) and THD Group (full line), at baseline, 6 and 12 months of follow-up.

have progressed to an incremental dialysis program (namely twice to thrice-weekly dialysis and free-protein diet) and 2 patients partially recovered their renal function. The main reasons for dropping out were loss of dietary adherence and/or reduction of residual renal function.

When compared to THD group, CDDP patients registered a lower number of hospitalizations and a lower need for expensive drugs. These findings, coupled with the $66 \%$ reduction in number of dialysis sessions (52 versus 156 sessions in THD Group in a year) allows to estimated that the cost of a CDDP patient is more than $60 \%$ less than that of a THD patient.

\section{Discussion}

This study shows that in selected ESRD patients, a CDDP is able to protect the RRF, to maintain urine volume output, to preserve a good nutritional status, to blunt the rapid $\beta 2$ microglobulin increase, and to allow better control of anemia and calcium-phosphate abnormalities. CDDP is also associated with a lower rate of hospitalization, reduced need of EPO and drugs used for the CKD-MBD treatment, thus leading to a significant cost-saving. CCDP may be considered as the first step of an incremental approach to hemodialysis treatment of ESRD.

Patients who entered the CDDP showed a better control of phosphatemia, BUN, PTH levels and higher albumin levels despite a lower RRF. It suggests that patients who had maintained consistent adherence to dietary treatment chose the CDDP whereas THD was chosen by patients with poor compliance to dietary prescriptions. In fact, dietary discipline is the first pre-requisite for a safe and successful CDDP.

In the CDDP group an effective urine volume output was maintained whereas it dramatically dropped in the THD patients. As a consequence, the interdialytic weight gain in CDDP patients was quite small, thus allowing low intradialytic ultrafiltration volumes. In turn, this may contribute to further preservation of the residual renal function and to limit cardiovascular damage. When compared to THD, CDDP was not associated with greater mortality risk (Figure 2) and hospitalization rate was much lower.

One of the main goals of the CKD patients care is to preserve RRF as long as possible because it is of very favorable prognostic value. The majority of patients succeeded in sticking to CDDP for at least one year ensuring a good nutritional status and maintaining GFR $(-1.56 \mathrm{ml} /$ $\mathrm{min} /$ year); in stage 4-5 CKD Levin et al. reported a GFR loss of $2.6 \mathrm{ml} / \mathrm{min} /$ year [17].

Three major studies investigated once a-weekly dialysis coupled with low protein regimens in ESRD patients [5-8]. Mitch et al. reported that combined diet-dialysis treatment resulted in a decrease in urea production with a positive nitrogen balance during interdialytic interval 
Table 3 Biochemistry parameters in CDDP and THD groups at 6 and 12 months

\begin{tabular}{|c|c|c|c|c|c|c|c|}
\hline & CDDP group & & & THD group & & & \\
\hline & $\begin{array}{l}\text { Baseline } \\
(\mathrm{n}=38)\end{array}$ & $\begin{array}{l}6 \text { months } \\
(\mathrm{n}=38)\end{array}$ & $\begin{array}{l}12 \text { months } \\
(\mathrm{n}=34)\end{array}$ & $\begin{array}{l}\text { Baseline } \\
(\mathrm{n}=30)\end{array}$ & $\begin{array}{l}6 \text { months } \\
(\mathrm{n}=30)\end{array}$ & $\begin{array}{l}12 \text { months } \\
(\mathrm{n}=29)\end{array}$ & $\mathbf{P}$ \\
\hline Triglycerides (mg/dL) & $109 \pm 36$ & $134 \pm 92$ & $126 \pm 50$ & $131 \pm 72$ & $152 \pm 67$ & $139 \pm 52$ & 0.03 \\
\hline Total Cholesterol (mg/dL) & $164 \pm 36$ & $168 \pm 36$ & $164 \pm 35$ & $165 \pm 41$ & $168.5 \pm 34$ & $170 \pm 40$ & 0.51 \\
\hline HDL Cholesterol (mg/dL) & $44 \pm 14$ & $47 \pm 13$ & $48 \pm 20$ & $44 \pm 12$ & $45 \pm 13$ & $44 \pm 12$ & 0.58 \\
\hline LDL Cholesterol (mg/dL) & $101 \pm 29$ & $93 \pm 34$ & $93 \pm 31$ & $95 \pm 32$ & $93 \pm 29$ & $97.8 \pm 34$ & 0.95 \\
\hline Cholinesterases (UI/mL) & $5474 \pm 1396$ & $6073 \pm 1474$ & $586 \pm 1646$ & $4968 \pm 1488$ & $5511 \pm 1604$ & $4673 \pm 1450^{b}$ & 0.27 \\
\hline Uric acid (mg/dL) & $7.3 \pm 2.3$ & $7.5 \pm 2.4$ & $7.1 \pm 1.9$ & $6.4 \pm 1.8^{b}$ & $7.3 \pm 1.2$ & $7.2 \pm 1.3^{b}$ & 0.60 \\
\hline Sodium (mmol/L) & $139 \pm 2.6$ & $137 \pm 3.6$ & $137 \pm 4.0$ & $138 \pm 2.7$ & $138 \pm 2.3$ & $134 \pm 3.3$ & 0.58 \\
\hline Potassium (mmol/L) & $4.4 \pm 0.6$ & $4.3 \pm 0.6$ & $4.3 \pm 0.7$ & $4.3 \pm 0,67$ & $4.7 \pm 0.7$ & $4.8 \pm 0.9^{b}$ & 0.07 \\
\hline Calcium (mg/dL) & $9.2 \pm 0.5$ & $9.0 \pm 0.5$ & $9.1 \pm 0.6$ & $9.1 \pm 0.6$ & $9.1 \pm 0.7$ & $9.0 \pm 0.5$ & 0.51 \\
\hline Phosphatemia (mg/dL) & $4.4 \pm 0.9$ & $4.6 \pm 0.8$ & $4.6 \pm 0.8$ & $5.1 \pm 1.5$ & $5.6 \pm 1.1$ & $5.2 \pm 1.1$ & 0.001 \\
\hline Bicarbonate (mEq/L) & $22.0 \pm 3.1$ & $23.1 \pm 3.3$ & $23.2 \pm 3.2$ & $21.8 \pm 4.2$ & $21.9 \pm 3.2$ & $21.6 \pm 2.7$ & 0.17 \\
\hline ß2-microglobulin (mg/dL) & $14.2 \pm 3.9$ & $16.8 \pm 5.7$ & $16.0 \pm 5.1$ & $18.4 \pm 11.6$ & $31.0 \pm 16.0$ & $28.0 \pm 11.4^{b}$ & 0.007 \\
\hline$H b(g / d)$ & $10.8 \pm 0.1$ & $11.5 \pm 0.95$ & $11.5 \pm 0.97^{a}$ & $10.5 \pm 1.4$ & $11.3 \pm 0.9$ & $11.2 \pm 0.95^{\mathrm{a}}$ & 0.31 \\
\hline EPO (IU/kg/week) & $104 \pm 108$ & $69 \pm 59$ & $60 \pm 74^{b}$ & $184 \pm 84$ & $172 \pm 138$ & $204 \pm 252$ & 0.002 \\
\hline ERI (IU/kg/week)/Hb & $10 \pm 11$ & $6 \pm 5$ & $5 \pm 7^{b}$ & $19 \pm 10$ & $15 \pm 13$ & $19 \pm 23$ & $<0.001$ \\
\hline$C R P$ (\% patients) $<5.0$ & 89 & 81.5 & 79 & 66.6 & 83.3 & 76.6 & $<0.05$ \\
\hline $\operatorname{CRP}(\mathrm{mg} / \mathrm{dL})$ & $3.3 \pm 3.9$ & $3.5 \pm 3.3$ & $3.2 \pm 3.6$ & $8.6 \pm 9.7$ & $4.9 \pm 6.5$ & $5.8 \pm 5.8$ & $<0.01$ \\
\hline iPTH $(\rho g / m L)<150(\%)$ & 39.5 & 52.6 & 52 & 36.7 & 43.3 & 34.5 & 0.09 \\
\hline iPTH ( $\rho g / m L) ~ 150-300(\%)$ & 29 & 29 & 30 & 13.3 & 20 & 27.6 & 0.26 \\
\hline iPTH $(\rho g / m L)>300(\%)$ & $31.5^{\mathrm{a}}$ & 18.4 & $18^{\mathrm{a}}$ & 50 & 36.7 & 37.9 & 0.02 \\
\hline
\end{tabular}

Changes versus baseline: ${ }^{\mathrm{a}} \mathrm{p}<0.01 ;{ }^{\mathrm{b}} \mathrm{p}<0.03$; P: ANOVA significance for treatment by time interaction.

[5]. Patients studied by Giovannetti et al. showed no uremic symptoms even after years of IDDP despite an extremely low RRF, thus indicating that the nutritional therapy is a major factor preventing the onset of uremic symptoms [6]. The studies carried out by Locatelli et al. concluded that IDDP may be very important from a psychological and economic point of view, but concerns arose about compliance and long-term nutritional and depurative adequacy [7]. After a 4-year period they found a reduction of creatinine generation rate, possibly suggesting a reduction in muscle mass.

This was not confirmed in our patients where the CDDP differs from the similar strategies proposed in the 1980's and 1990's [6,7]; the treatment is distinguished by less severe residual renal function from among patients, less severe protein restriction, and by closer nutritional monitoring. In addition, hemodialysis sessions were performed with high quality water and highly bio-compatible membranes [18-21].

Retrospective and prospective studies failed to demonstrate any benefits, in terms of survival, for an early onset of dialysis. In 2010 the first randomized, controlled trial of early versus late initiation of dialysis reported that early access to dialysis (eGFR $>7 \mathrm{ml} / \mathrm{min}$ / $1.73 \mathrm{~m}^{2}$ ) provided no statistically significant benefits in terms of patient survival [22]. 


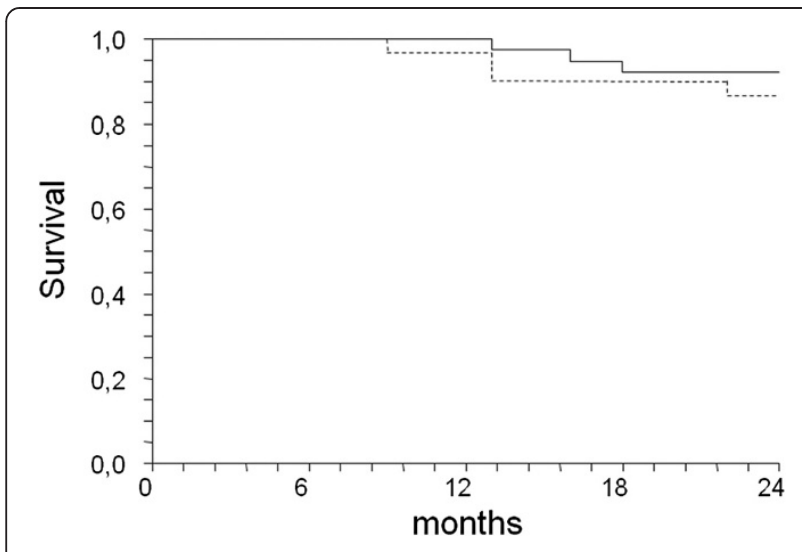

Figure 2 Cumulative survival in CDDP group (Dotted line) and in THD Group (Full line).

The role played by RRF in the clearance of mediumsized molecules such as $\beta 2$-microglobulin is wellknown (Figure 1c). Accordingly, patients with a significant RRF manifest lower levels of $\beta 2$-microglobulin. On commencing CDDP, maintenance of effective urine output volume, a better hyperparathyroidism control, and a good nutritional status may have produced a positive effect on erythropoiesis leading to better anemia correction with reduction of ERI [23-25]. Our findings are in keeping with those of $\mathrm{Di}$ Iorio et al. who demonstrated that a poorer response to EPO was related to secondary hyperparathyroidism [23]. At baseline, in 50\% of THD patients PTH was $>300 \mathrm{pg} / \mathrm{ml}$ with significantly higher serum phosphate levels and a significantly lower use of calcimimetic drugs compared to CDDP Group (Tables 3 and 4). During the study, CDDP patients had no need for additional dialysis sessions. In turn, an easy volumes balance with quite low interdialytic weight gains, and prevention of high ultrafiltration rates and of intradialytic hypotension, contribute to the protection of RRF during CDDP. Moreover, Fouque et al. showed that dietary treatment produced a positive effect in delaying the need of dialysis [26].

It is noteworthy that the hospitalization rate in CDDP was much lower than in THD Group. In the latter, the causes of admission were mainly vascular access complications and infection. In addition the overall 2 year-survival rate of CDDP was similar to that of THD patients. In fact, data from literature show that a conservative approach may be not inferior to dialysis in elderly ESRD patients, in terms of survival and/or quality of life [27-29].

Lastly, the CDDP treatment resulted in an approximate $50 \%$ savings on the cost of drugs and dialysis resources, including a lower number of dialysis hours/ nursing and medical staff ( $66 \%$ less compared to thriceweekly hemodialysis) and comorbid incidence in terms of days of hospitalization, as well as of indirect costs such as transport of patients to and from the dialysis unit. When compared to THD, the CDDP group showed a lower hospitalization rate, lower need for expensive drugs, and by definition a $66 \%$ lowering of number of dialysis sessions and related costs. CDDP patients may have the additional cost of the protein-free products. As a whole, CDDP seems to be a safe and effective exit strategy for lowering the cost of ESRD population, even if it can occur for a limited period of time and in selected ESRD patients.

Another advantage of CDDP is an improvement in patient's acceptance and adaptation to renal replacement therapy. The patient feels less sick and less machine-dependent, resulting in an increased copying capacity (or psychological adaptation). Patients moreover tended to adapt better to low protein diets thanks to a more varied diet, as well as to address concerns about "dialysis-day", which was also the day they were allowed to eat a "normal" diet.

The study has not had the opportunity to randomize and this may be seen as a limitation, but randomization was not feasible because one could not force patients to choose one method rather than the other. Patients were followed in pre-dialysis care: a multidisciplinary clinic (doctors, nurses, dietitians and psychologists) was able to provide the necessary education and choice of treatment modalities. This study aimed to reproduce the real world clinical practice where patient's adherence is a crucial issue for the success of any treatment, especially if dietary in nature, where patients play an active role and must be involved in the decision-making process. Patients who entered the CDDP showed a lower residual renal function but better control of phosphatemia, BUN, PTH levels and higher albumin levels. This finding suggests that CDDP is suitable for patients who still have a positive inclination towards dietary manipulations. Moreover, together with a preserved urine output volume, good compliance to dietary prescriptions is mandatory and a pre-requisite for the success and safety of CDDP. Now it could be necessary to begin considering a tailored dialytic treatment and to evaluate the greater power of RRF. The incremental choice is considered a good option in peritoneal patients since the 2000's [30,31] thanks to RRF and it again underestimates for twice-weekly HD patients [32,33]. Energyadequate low-protein regimens have a fundamental role in controlling and maintaining a good metabolic status and in reducing GFR loss $[26,34]$.

\section{Conclusions}

This study shows that in selected ESRD patients, a CDDP is able to protect the RRF, to maintain urine volume output, to preserve a good nutritional status, to blunt the rapid $\beta 2$ microglobulin increase, and to allow better control of anemia and calcium-phosphate abnormalities. CDDP is also associated with a lower rate of hospitalization and reduced need of EPO and drugs used for the CKD-MBD treatment, thus leading to a significant cost-saving. As a whole, our 
findings suggest that CDDP could be a beneficial choice for selected collaborative patients who would otherwise be referred to thrice-weekly hemodialysis. CCDP should be considered as the first step of an incremental approach to hemodialysis treatment in motivated and selected ESRD patients, or anywhere dialysis facilities and resources are lacking.

\section{Abbreviations}

ADPK: Autosominal dominant polycystic kidney disease; CDDP: Combined diet dialysis program; THD: Thrice-weekly dialysis; IDDP: Integrated diet dialysis program; RRF: Residual renal function; CKD: Chronic kidney disease; ESRD: End stage renal disease; GFR: Glomerular filtration rate; eGFR: Estimated glomerular filtration rate; CKD-MBD: Chronic kidney disease- mineral bone disorders; HD: Hemodialysis; ERI: Erythropoietin resistance index.

\section{Competing interests}

All authors declare that it doesn't exist any competing interest before and after publication, financial relationship with other people and organizations.

\section{Authors' contributions}

SC made substantial contributions to conception and design, acquisition of data, analysis, writing and interpretation of data, and drafting of the manuscript. AC made substantial contributions to conception and design, was involved in the interpretation of data, drafting of the manuscript and critical revisions. GS was involved in the acquisition of data. PB made and begun conception and design of CDDP, was involved in analysis and interpretation of data, and drafting of the manuscript and critical revisions. All authors read and approved the final manuscript. All authors read and approved the final manuscript.

\section{Acknowledgements}

The Authors are gratefully indebted to Dr. Claudia D'Alessandro (R.D.) for her important contribution on the dietetic aspects of the study, and to Mr. Otto Miller for his careful editing of the manuscript.

\section{Author details}

${ }^{1}$ Nephrology and Dialysis Unit, ASL 8 Cagliari, Italy. ${ }^{2}$ Department of Clinical and Experimental Medicine, University of Pisa, Pisa, Italy. ${ }^{3}$ Nephrology and Dialysis Unit, Brotzu Hospital, Cagliari, Italy.

Received: 29 June 2014 Accepted: 15 October 2014

Published: 29 October 2014

\section{References}

1. US Renal Data System: USRDS 2006 Annual Data Repost: Atlas of End-Stage Renal Disease in the United States. Bethesda MD: National Institutes of Health, National Institutes of Diabetes and Digestive and Kidney Disease; 2007.

2. Coresh J, Selvin E, Stevens LA, Manzi J, Kusek JW, Eggers P, Van Lente F, Levey AS: Prevalence of chronic kidney disease in the United States. JAMA 2007, 298:2038-2047.

3. Hallan SI, Dahl K, Oien CM, Grootendorst DC, Aasberg A, Holmen J, Dekker FW: Screening strategies for chronic kidney disease in the general population: follow-up of cross sectional health survey. BMJ 2006, 18:1047-1052

4. De Zeeuw D, Hillege HL, de Jong PE: The kidney, a cardiovascular risk marker and a new target for therapy. Kidney Int Supp/ 2005, 98:S25-S29.

5. Mitch WE, Sapir DG: Evaluation of reduced dialysis frequency using nutritional therapy. Kidney Int 1981, 20:122-126

6. Morelli E, Baldi R, Barsotti G, Ciardella F, Cupisti A, Dani L, Mantovanelli A, Giovannetti S: Combined therapy for selected chronic uremic patients: infrequent hemodialysis and nutritional management. Nephron 1987, 47:161-166.

7. Locatelli F, Andrulli S, Pontoriero G, Di Filippo S, Bigi MC: Supplemented low- protein diet and once weekly hemodialysis. Am J Kidney Dis 1994, 24:192-204.

8. Cardelli R, D'Amicone M, Manzione A, Gurioli L, Grotti G, Biselli L, Priasca G, Agagliati D: Weekly dialysis combined with low-protein diet and essential amino acids. Preliminary data. Minerva Urol Nefrol 1991, 43:211-216.
9. Brauer $\mathrm{JH}$, Brooks $\mathrm{CS}$, Burch RN: Renal function studies in man with advanced renal insufficiency. Am J Kidney Dis 1982, 2:30-35.

10. Poggio ED, Wang X, Greene T, Van Lente F, Hall PM: Performance of the modification of diet in renal disease and Cockcroft-Gault equations in the estimation of GFR in health and in chronic kidney disease. J Am Soc Nephrol 2005, 16:459-466.

11. Maroni BJ, Steinman TI, Mitch WE: A method for estimating nitrogen intake of patients with chronic renal failure. Kidney Int 1985, 27:58-65.

12. Daugirdas J: Second generation logarithmic estimates of single-pool variable volume Kt/V: an analysis of error. J Am Soc Nephrol 1993, 4:1205-1213.

13. Locatelli F, Andrulli S, Memoli B, Maffei C, Del Vecchio L, Aterini S, De Simone W, Mandalari A, Brunori G, Amato M, Cianciaruso B, Zoccali C: Nutritional-inflammation status and resistance to erythropoietin therapy in hemodialysis patients. Nephrol Dial Transpl 2006, 21:991-998.

14. Charlson M, Szatrowski TP, Peterson J, Gold J: Validation of a combined comorbidity index. J Clin Epidemiol 1994, 47:1245-1251.

15. Cupisti A, Kalantar-Zadeh K: Management of natural and added dietary phosphorus burden in kidney disease. Semin Nephrol 2013, 33:180-190

16. D'Alessandro C, Rossi A, Innocenti M, Ricchiuti G, Bozzoli L, Sbragia G, Meola M, Cupisti A: Dietary protein restriction for renal patients: don't forget protein-free foods. J Ren Nutr 2013, 23:367-371.

17. Levin A, Djurdjiev O, Beaulieu M, Er L: Variability and risk factors for kidney disease progression and death following attainment of stage 4 CKD in a referred cohort. Am J Kidney Dis 2008, 52:661-671.

18. Sciffl H, Lang SM, Stratakis D, Fischer R: Effects of ultrapure dialysis fluid on nutritional status and inflammatory parameters. Nephrol Dial Transplant 2001, 16:1863-1869.

19. Schouten WE, Grooteman MP, van Houte AJ, Schoorl M, van Limbeek J, Nube MJ: Effects of dialyser and dialysate on the acute phase reaction in clinical bicarbonate dialysis. Nephrol Dial Transplant 2000, 15:379-384

20. Maduell F, Navarro V, Cruz MC, Torregrosa E, Garcia D, Simon V, Ferrero $J A$ : Osteocalcin and myoglobin removal in on-line hemodiafiltration versus low- and high-flux hemodialysis. Am J Kidney Dis 2002, 40:582-589.

21. Vanholder R, Glorieux G, Van Biesen W: Advantages of new hemodialysis membranes and equipment. Nephron Clin Pract 2010, 114:c165-c172.

22. Cooper BA, Branley P, Bulfone L, Collins JF, Craig JC, Fraenkel MB, Harris A, Johnson DW, Kessehut J, Li JJ, Luxton G, Pilmore A, Tiller DJ, Harris DC, Pollock CA, for the IDEAL Study: A randomized controlled trial of early versus late initiation of dialysis. N Engl J Med 2010, 363:606-619.

23. Di lorio BR, Minutolo R, De Nicola L, Bellizzi V, Catapano F, lodice C, Rubino R, Conte G: Supplemented very low protein diet ameliorates responsiveness to erythropoietin in chronic renal failure. Kidney Int 2003, 64:1822-1828.

24. Stenvinkel $\mathrm{P}$, Bàràny $\mathrm{P}$ : Anemia, rHuEPO resistance and cardiovascular disease in end-stage renal failure: links to inflammation and oxidative stress. Nephrol Dial Transplant 2002, 17(Suppl 5):S32-S37.

25. Filipowicz R, Beddhu S: Optimal nutrition for predialysis chronic kidney disease. Adv Chronic Kidney Dis 2013, 20:175-180.

26. Fouque D, Wamg P, Laville M, Boissel JP: Low protein diets delay end-stage renal disease in non diabetic adults with chronic renal failure. Nephrol Dial Transplant 2000, 15:1986-1992.

27. Chandna SM, Da Silva-Gane M, Marshall C, Warwicker P, Greenwood RN, Farrington K: Survival of elderly patients with stage 5 CKD: comparison of conservative management and renal replacement therapy. Nephrol Dial Transplant 2011, 26:1608-1614.

28. Da Silva-Gane M, Wellsted D, Greenshields H, Norton S, Chandna SM, Farrington K: Quality of life and survival in patients with advanced kidney failure managed conservatively or by dialysis. Clin J Am Soc Nephrol 2012, 7:2002-2009.

29. Brunori G: Treatment of chronic kidney disease in the elderly: diet or conservative management. J Nephrol 2012, 25(Suppl 19):S28-S31.

30. I National Kidney Foundation - K/DOQI: update 2000. Am J Kidney Dis 2001, 37(Suppl 1):S7--S64.31.

31. Kalantar-Zadeh K, Casino FG: Let us give twice-weekly hemodialysis a chance: revisiting the taboo. Nephrol Dial Transplant 2014, 29(9):1618-1620.

32. European best practice guidelines expert group on haemodialysis. Nephrol Dial Transplant 2002, 17(Suppl 7):S16-S31. 
33. Rhee CM, Unruh M, Chen J, Kovesdy CP, Zage P, Kalantar-Zadeh K Infrequent dialysis: a new paradigm for hemodialysis initiation. Semin Dial 2013, 26:720-727.

34. Cupisti A, D' Alessandro C, Morelli E, Manca Rizza G, Galetta F, Franzoni F, Barsotti G: Nutritional status and dietary manipulation in predialysis chronic renal failure patients. J Ren Nutr 2004, 14:127-133.

doi:10.1186/1471-2369-15-172

Cite this article as: Caria et al:: The incremental treatment of ESRD: a

low-protein diet combined with weekly hemodialysis may be beneficial

for selected patients. BMC Nephrology 2014 15:172.

\section{Submit your next manuscript to BioMed Central and take full advantage of:}

- Convenient online submission

- Thorough peer review

- No space constraints or color figure charges

- Immediate publication on acceptance

- Inclusion in PubMed, CAS, Scopus and Google Scholar

- Research which is freely available for redistribution 